\title{
Concept learning through question framing in Pharmacology
}

\author{
Syam Sreedharan, Hyma Vijayalekshmi, Dhanya S. Palappallil*
}

Department of Pharmacology, Government Medical College, Kottayam, Kerala, India

Received: 11 December 2017 Accepted: 02 January 2018

\section{*Correspondence to:}

Dr. Dhanya S. Palappallil, Email: drspdhanya@gmail.com

Copyright: (C) the author(s), publisher and licensee Medip Academy. This is an openaccess article distributed under the terms of the Creative Commons Attribution NonCommercial License, which permits unrestricted noncommercial use, distribution, and reproduction in any medium, provided the original work is properly cited.

\begin{abstract}
Background: Framing questions is a skill that requires expertise, knowledge, guidance and mentoring. It provides structure for deep learning, critical thinking and also promotes interaction and communication. Objective of this study is to analyze the question framing skills of fifth semester medical students on a 'must know' area in Pharmacology.

Methods: A cross-sectional study was done in the Department of Pharmacology of a Government Medical College in Central Kerala. After briefing about the study, each of the participants was instructed to frame a question which were collected after 15 minutes. The data on different aspects of questions was analysed by Statistical Package for the Social Sciences 16.

Results: Total 130 students, 79 females and 51 males participated in this study. 7 questions were incomplete and excluded from further analysis. From the rest 123 properly framed questions, $106(86.2 \%)$ were correct, $10(8.1 \%)$ were partially correct and 7(5.7\%) incorrect with regards to the task assigned. In this study knowledge as well as application was tested in 50.4\% questions, comprehension in $21.1 \%$ and application alone in $22.8 \%$. The knowledge dimension tested was factual in $91(74 \%)$ and conceptual in 32(26\%). Non-hierarchical classification showed 96(78\%) convergent and 27(22\%) divergent.

Conclusions: In this study majority of the participants framed direct short answer questions which reflects factual knowledge indicating their lower-level cognition. Critical thinking and procurement of higher level cognition can be attained by directing them to frame the right question especially in medical education.
\end{abstract}

Keywords: Concept learning, Cognition dimension, Critical thinking, Innovative learning, Knowledge dimension, Question framing

\section{INTRODUCTION}

Asking good question is an art. Organization of scientific data into facts requires questioning and reasoning by intellectual exploration. ${ }^{1}$ Framing flawless questions requires expertise, knowledge, guidance and mentoring. Socratic questioning which probes the validity of an assumption is advocated as a powerful modern-day teaching-learning method. ${ }^{2}$ When used tactically, questioning ensures dynamic participation in deep learning. ${ }^{3}$ Fact based questions are good for building confidence and assessing knowledge of novice learners. Questioning can help students in comprehending a concept enticing them to search for rational conclusions rather than resorting to learning by rote. Learning to ask the right question the right way makes question framing a precious teaching-learning-assessment tool. ${ }^{4}$ This study was done with an aim to analyze the question framing skills of fifth semester medical students on a 'must know' area in Pharmacology.

\section{METHODS}

This was a cross-sectional study done in the Department of Pharmacology of a Government Medical College in Central Kerala during a pharmacology session in November 2017. Since there were no ethical issues the clearance from Ethics Committee was not sought. All students who were willing to participate in the study were included after getting informed consent. The use of 
"adrenaline in anaphylactic shock" was chosen as the "must know" area in this study. During a Pharmacology Lecture hour, the study participants were briefed on the same by the Principal Investigator. After completing the session each of the participants was instructed to frame a question which would close on to the answer "Adrenaline 0.5 milligram Intramuscular Statim". After 15 minutes the questions were collected. The questions were reviewed, and data were entered in a structured proforma by the investigators. Apart from age and gender the 10 parameters studied were completeness, correctness, structure, clinically oriented or not, case based or not, mention of symptoms correctly if case based, type-essay or short answer question (SAQ), Nonhierarchical classificationconvergent /divergent, Cognition dimension Knowledge/Comprehension/Application/Analysis/Synthe sis/ Evaluation and Knowledge Dimension-Factual/ Conceptual. The incomplete questions were excluded from further analysis. The data was sorted, coded and entered into Statistical Package for the Social Science (SPSS) software version 16 (SPSS Inc, Chicago, USA). Descriptive data were expressed using frequencies and percentages. Chi square analysis was done to find any influence of gender on the nonhierarchical classification, the knowledge dimension and the cognition dimension.

\section{RESULTS}

Out of the 149 students in fifth semester in the institution 130 students willingly participated in this innovative teaching-learning process. Of the 130 participants, 79 $(60.8 \%)$ were females and $51(39.2 \%)$ were males as shown in Figure 1. The mean age of the participants was $20.16 \pm 0.69$ years, age range was 19 to 25 years. Even though all $130(100 \%)$ participants attempted framing a suitable question $7(5.4 \%)$ were incomplete as they had only the stem of a case based question and hence excluded from further analysis.

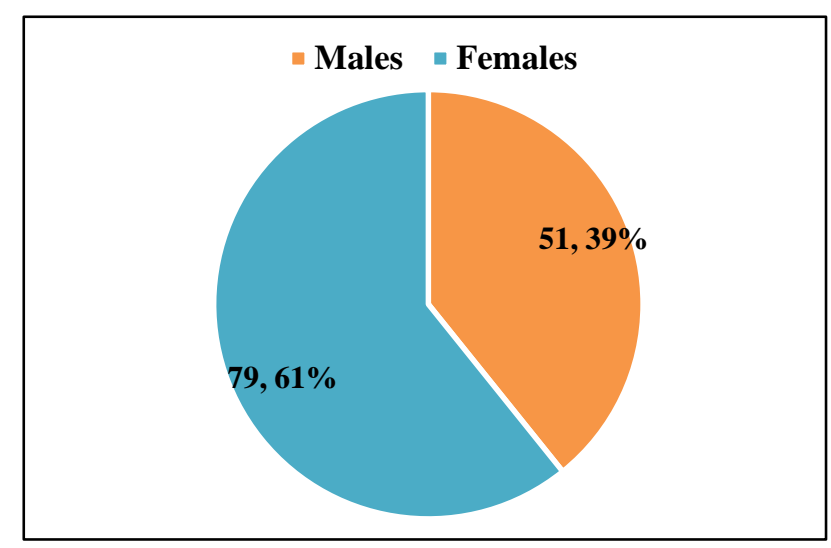

Figure 1: Gender-wise distribution of participants.

Of the 123 properly framed questions, $106(86.2 \%)$ were correct, $10(8.1 \%)$ were partially correct and $7(5.7 \%)$ incorrect with regards to the task assigned. None of the questions were structured. Of the 49 (39.8\%) clinically oriented questions $32(26 \%)$ were case based and mentioned the symptoms of the patient in the scenario correctly as shown in Table 1.

\section{Table 1: Profile of framed questions which were complete.}

\begin{tabular}{|ll|}
\hline Type & n (\%) \\
\hline Clinically oriented & $74(60.2)$ \\
\hline No & $49(39.8)$ \\
\hline Yes & \\
\hline Case based & $91(74)$ \\
\hline No & $32(26)$ \\
\hline Yes & \\
\hline Symptoms mentioned & $93(75.6)$ \\
\hline No & $30(24.4)$ \\
\hline Yes & $7(5.7)$ \\
\hline Appropriate for the task assigned \\
\hline Incorrect & $10(8.1)$ \\
\hline Partially correct & $106(86.2)$ \\
\hline Correct & \\
\hline Type & $27(22)$ \\
\hline Essay & $96(78)$ \\
\hline Short Answer Question & \\
\hline Knowledge dimension & $32(26)$ \\
\hline Conceptual & $91(74)$ \\
\hline Factual & $96(78)$ \\
\hline Non-hierarchical classification & \\
\hline Convergent & $27(22)$ \\
\hline Divergent & \\
\hline
\end{tabular}

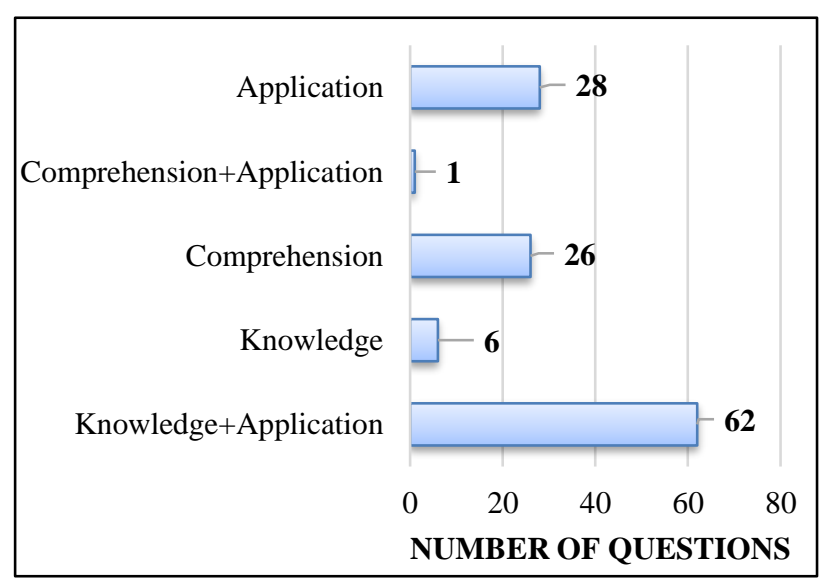

Figure 2: Classification of questions based on cognition level.

About 27 (22\%) were essay type and the rest were $96(78 \%)$ were short answer questions. About $78 \%$ were convergent and the rest divergent. The knowledge dimension tested was factual in $91(74 \%)$ and conceptual in $32(26 \%)$. The cognitive dimension tested was both knowledge and application in 62(50.4\%) questions, comprehension in $26(21.1 \%)$, application alone in 28(22.8\%) as shown in Figure 2. Gender wise there was no statistically significant difference in the knowledge dimension (chi square=2.142, $\mathrm{p}=0.14$ ) or cognition 
dimension (chi square $=2.35, \mathrm{p}=0.79$ ) or nonhierarchical classification as convergent or divergent questions (chi square $=0.94, p=0.33$ ). Table 2 summarizes a sample of different types of questions framed by the participants.

Table 2: Sample questions framed by participants.

\begin{tabular}{|c|c|c|c|c|c|c|c|c|}
\hline Question & Structured & $\begin{array}{l}\text { Clinically } \\
\text { oriented }\end{array}$ & $\begin{array}{l}\text { Case } \\
\text { based }\end{array}$ & $\begin{array}{l}\text { Symptoms } \\
\text { mentioned }\end{array}$ & Essay/SAQ & $\begin{array}{l}\text { Knowledge } \\
\text { dimension }\end{array}$ & $\begin{array}{l}\text { Cognition } \\
\text { dimension }\end{array}$ & $\begin{array}{l}\text { Non } \\
\text { hierarchical }\end{array}$ \\
\hline \multicolumn{9}{|c|}{ 1. What is the drug of choice of anaphylaxis? What is the dose and route of administration? } \\
\hline & No & No & No & No & SAQ & Factual & $\begin{array}{l}\text { Knowledge+ } \\
\text { Application }\end{array}$ & Convergent \\
\hline \multicolumn{9}{|c|}{$\begin{array}{l}\text { 2. A } 40 \text { year old woman came with complains of cough, fever and expectoration for } 2 \text { days. The patient was examined and } \\
\text { diagnosed as upper respiratory tract infection. Drug Amoxicillin 500mg TDS was prescribed. On taking the patient } \\
\text { experienced hypotension, bradycardia and went on to shock. What will you do? }\end{array}$} \\
\hline & No & Yes & Yes & Yes & Essay & Conceptual & Comprehension & Divergent \\
\hline \multicolumn{9}{|c|}{ 3. A patient who took paracetamol showed hypersensitivity reactions. which is the drug of choice, route and dosage? } \\
\hline & No & Yes & No & No & SAQ & Factual & $\begin{array}{l}\text { Knowledge+ } \\
\text { Application }\end{array}$ & Convergent \\
\hline \multicolumn{9}{|c|}{ 4. A 25 year old male presented to the casualty with hypersensitivity to pollen. What is the drug of choice? } \\
\hline & No & Yes & No & No & SAQ & Factual & Application & Convergent \\
\hline \multicolumn{9}{|c|}{$\begin{array}{l}\text { 5. A patient presents with anaphylactic shock. What is the dose of adrenaline to be administered to the patient who weighs } 50 \\
\mathrm{~kg} \text { ? }\end{array}$} \\
\hline & No & No & No & No & SAQ & Factual & Knowledge & Convergent \\
\hline \multicolumn{9}{|c|}{ lactic shock? Or How will you manage anaphylactic shock? } \\
\hline & No & No & No & No & Essay & Conceptual & Comprehension & Divergent \\
\hline
\end{tabular}

\section{DISCUSSION}

Questioning is one of the many teaching-learning stratagems thought to expedite the development of analytical expertise which is essential in medical education. ${ }^{5}$ Teachers ask questions to assess the learner, to sustain the interaction in an interesting way and to generate discussions comprehensively exploring the subject. ${ }^{3}$ Bloom's taxonomy of learning consists of six domains of cognition; knowledge, comprehension and application domains at the lower-order and analysis, synthesis and evaluation domains at the higher-order. ${ }^{6}$ Student initiated questions are deemed to be of the higher order. ${ }^{7}$ This research work was done as a part of innovative learning session in pharmacology in a Government Medical College in Central Kerala. Similar publications among medical undergraduates is sparse.

Adrenaline is a life-saving drug acting on both $\alpha$ and $\beta$ receptors with potent vasoconstrictor and cardiac stimulant actions. ${ }^{8}$ Secreted from the adrenal medulla it functions as hormone under physiologic conditions. It is used in the emergency management of complete heart block and cardiac arrest during resuscitation. Adrenaline is an effective haemostatic agent used topically in nasal packs for epistaxis or in gingival string for gingivectomy. It is combined with some local anaesthetics to prolong the duration of nerve block, to reduce the total dose of local anaesthetic and to reduce its toxicity in a dose of 1:200,000. Widespread experimental and clinical experience with use of adrenaline in anaphylaxis support it as the agent of choice in anaphylaxis in a dose of 0.3-0.5 $\mathrm{mg}$ (0.3-0.5 ml of 1:1000 solution) intramuscularly. Epipen (epinephrine in an autoinjector for selfadministration) is recommended for patients at risk for insect sting hypersensitivity, food allergies or other anaphylaxis. In this study the students were asked to frame a question which would fetch the answer "Adrenaline 0.5mg 1:1000 intramuscularly." The questions were then evaluated on a ten-point criteria.

Of the 130 participants 7 were excluded as they had written only the clinical scenario related to anaphylaxis with no subsequent questions and hence incomplete. Of the 123 complete questions $8.1 \%$ mentioned some symptoms of anaphylaxis incorrectly and hence were partially correct and $5.7 \%$ framed the questions incorrectly as they had asked wrong questions like "treatment for hypotension during surgery" or "treatment of dapsone syndrome." Dapsone syndrome is a rare dose independent adverse effect reported with dapsone use. It is a delayed hypersensitivity reaction which can occur after several weeks to up to six months after treatment initiation. The management involves prompt discontinuation of the offender, systemic steroids (prednisolone $1 \mathrm{mg} / \mathrm{kg} /$ day oral or methylprednisolone intravenous) with supportive care. ${ }^{9}$ Based on the Dreyfus model of skill acquisition classified the learners into novice who function by using limited knowledge system without clinical milieu, advanced beginners with expanded gamut of clinical rules with some clinical contact, competent when they use rules of thumb and are in the process of getting devoted in patient care and 
proficient who show increasing initiative in patient care with intuitive clinical reasoning based on their previously gained clinical experience. ${ }^{10,11}$ Structured questions are closed end questions and both essay questions and short answer questions can be structured. They help candidates construct their own answer and yet encourage sufficient precision for answers and reflect participatory teaching and self-directed learning. ${ }^{12}$ In this study, none of the questions were structured. By the fifth semester of medical education in India the students receive one and a half years of clinical exposure and help them to correlate the concepts in Pharmacology. The clinical pharmacology exercises like patient oriented problem solving exercises generate clinical orientation pertaining to the treatment of disease in correlation with the pharmacological concepts. ${ }^{13}$ Casebased learning have been well-implemented into the undergraduate curriculum with due stress on active learning during seminars and other innovative sessions. ${ }^{14}$ In this study, $39.8 \%$ were clinically oriented questions mentioning a history of hypersensitivity either following a drug administration or food intake or pollen exposure. About 26\% were case based questions which described the clinical scenario with symptoms in detail.

Essay questions challenge students to create a response rather than to simply select a response and they reveal students' abilities to reason, create, analyze, synthesize, and evaluate. ${ }^{15}$ Focused essay questions help to assess the depth of learning whereas less-focused essay questions are apt to gauge the breadth of learning within a subject. Shortanswer questions (SAQs) may be open-ended or closed and require students to create an answer and test the lower levels of the cognitive domain, mainly knowledge, comprehension, and some application. Divergent questions are open, might elicit numerous responses and permits the probe into an assortment of outlook encouraging dialogue while convergent questions congregate into a single or narrow list of best answers encouraging succinct response. ${ }^{3}$ In this research (27)22\% framed questions were essay type and the rest $96(78 \%)$ were short answer questions. Similarly $22 \%$ were divergent in nature and $78 \%$ were convergent type questions.

Anderson and Krathwohl described Knowledge dimensions as factual, conceptual, procedural and metacognitive on the basis of which questions may be classified. ${ }^{16}$ Factual questions extract information from reliable sources. They demonstrate understanding, prompt analysis or evaluate work of others. Conceptual questions seeks justification based on underlying principles or theories. Procedural questions gathers well established methods of information and metacognitive questions require articulation of a cognitive strategy required to complete a task. ${ }^{16}$ In our study, $74 \%$ were factual and the rest conceptual questions. Classification of question based on cognition dimension was proposed by Bloom. ${ }^{6}$ In this study knowledge as well as application was tested in $50.4 \%$ questions, comprehension in $21.1 \%$ and application alone in $22.8 \%$. The cognition level tested was low.
Lower-level cognitive questions do not effectively stimulate critical thinking. ${ }^{17}$ The majority of participants (nursing students and tutors) framed factual questions at low-level aimed at seeking yes/no responses. ${ }^{18}$ Gender wise there was no statistically significant difference in the knowledge dimension, cognition dimension or nonhierarchical classification of the questions framed.

\section{CONCLUSION}

In this study majority of the participants framed direct short answer questions which elicited succinct response in the form of factual knowledge testing the lower-level cognition to accomplish the task assigned to them. However, critical thinking is a fundamental competency expected in medical profession to handle unique and uncertain situations. Medical undergraduates should be trained to judge a clinical scenario at a higher cognition level and should be lured into asking questions which require analysis, evaluation and synthesis rather than mere recall.

\section{ACKNOWLEDGEMENTS}

Authors are thankful to the students of $5^{\text {th }}$ semester of this institution who participated in this study.

Funding: No funding sources

Conflict of interest: None declared

Ethical approval: Not required

\section{REFERENCES}

1. Vale RD. The value of asking questions. Molecular Biology of the Cell. 2013;24:680-2.

2. Brill G, Yarden A. Learning biology through research papers: a stimulus for question-asking by high-school students. CBE Life Sci Educ. 2013;2:266-74.

3. Tofade T, Elsner J, Haines ST. Best practice strategies for effective use of questions as a teaching tool. Am J Pharm Educ. 2013;77(7):155.

4. Long M, Blankenburg R, Butani L. Questioning as a Teaching Tool. Pediatrics. 2015:135(3):406-8.

5. Philips N, Duke M. The questioning skills of clinical teachers and preceptors: a comparative study. J Adv Nurs. 2001;33(4):523-9.

6. Bloom BS. Taxonomy of Educational Objectives: The Classification of Educational Goals: Handbook 1: Cognitive Domain. New York: David McKay Co Inc; 1956.

7. Ciardiello AV. Did you ask a good question today? Alternative cognitive and metacognitive strategies. J Adolesc Adukt Lit. 1998;42(3):210-9.

8. Katzung BG, Masters SB, Trevor AJ. Basic and Clinical Pharmacology. 12 ${ }^{\text {th }}$ Ed. New Delhi: Tata McGraw-Hill; 2009.

9. Vinod KV, Arun K, Dutta TK. Dapsone hypersensitivity syndrome: A rare life threatening complication of dapsone therapy. J Pharmacol Pharmacother. 2013;4(2):158-60. 
10. Dreyfus SE. The Five-Stage Model of Adult Skill Acquisition. Bulletein of Sci Tech Soc. 2004;24(3):177-81.

11. Carraccio CL, Benson BJ, Nixon LJ, Derstine PL. From the educational bench to the clinical bedside: Translating the Dreyfus developmental model to the learning of clinical skills. Acad Med. 2008;83(8):7617.

12. Webber RH. Structured short answer questions: An alternative examination method. Med Educ. 1992;26(1):58-62.

13. Palappallil DS, Gangadhar R. Effectiveness of Revised Pharmacology Record Books as a TeachingLearning Method for Second Year Medical Students. J Clin Diagn Res. 2016;10(1):FC05-FC08.

14. Palappallil DS, Sushama J, Ramnath SN. Effectiveness of modified seminars as a teachinglearning method in pharmacology. Int $\mathbf{J}$ Appl Basic Med Res. 2016;6(3):195-200.

15. Reiner CM, Bothell TW, Sudweeks RR, Wood B. Preparing Effective Essay Questions. A Self-directed Workbook for Educators. New Forums Press; 2002. Available
https://testing.byu.edu/handbooks/WritingEffectiveEs sayQuestions.pdf Last accessed on 12/03/2017.

16. Anderson LW, Krathwohl DR, Airasian PW. A Taxonomy for Learning, Teaching, And Assessing: A Revision of Bloom's Taxonomy of Educational Objectives, $2^{\text {nd }} \mathrm{Ed}$, abridged. Boston, MA: Pearson Allyn \& Bacon; 2001.

17. Saeed T, Khan S, Ahmed A, Gul R, Cassum S, Parpio Y. Development of student's critical thinking: the educator's ability to use questioning skills in baccalaureate programmes in nursing in Pakistan. $\mathbf{J}$ Pak Med Assoc. 2012;63(3):200-3.

18. Profetto-McGrath J, Smith KB, Day RA, Yonge O. The questioning skills of tutors and students in a context based baccalaureate nursing program. Nurse Education Today. 2004;24:363-72.

Cite this article as: Sreedharan S, Hyma V, Palappallil DS. Concept learning through question framing in Pharmacology. Int J Basic Clin Pharmacol 2018;7:319-23. 